\title{
PAKAN BUATAN UNTUK PENGEMBANGAN BUDIDAYA IKAN DISCUS (Symphysodon discus) DI INDONESIA
}

\author{
Eni Kusrini") dan Bambang Priono") \\ 'Balai Riset Budidaya Ikan Hias \\ Jl. Perikanan No. 13, Pancoran Mas, Depok \\ E-mail: ennyperikanan@yahoo.com \\ ") Pusat Penelitian dan Pengembangan Perikanan Budidaya \\ Jl. Ragunan 20, Pasar Minggu, Jakarta Selatan 12540
}

\begin{abstract}
ABSTRAK
Ikan discus termasuk ikan hias yang agak sulit untuk dibudidayakan sehingga para pembudidayanya masih sangat terbatas. Cara budidaya yang sekarang sudah berkembang adalah masih secara konvensional. Larva ikan discus yang baru menetas sampai berumur satu minggu masih diasuh induknya karena masih tergantung dari lendir induk sebagai sumber makanannya, sehingga akan menunda induk lebih lama memijah berikutnya dan kanibalisme dapat terjadi terhadap larvanya sendiri. Artificial food (pakan buatan) yang terbuat dari telur ayam yang dibuat menyerupai lendir induk ikan discus merupakan sebuah inovasi dari pembudidaya ikan discus. Pemberian pakan buatan tersebut selain dapat memacu pematangan gonad induk ikan discus juga dapat menyelamatkan larva yang biasanya dimakan oleh induk-induknya (mengurangi kanibalisme).
\end{abstract}

KATA KUNCI: $\quad$ ikan discus, artificial food, matang gonad

\section{PENDAHULUAN}

Ikan discus, Symphysodon discus termasuk famili Cichlidae yang berasal dari perairan tenang di Sungai Amazon. Ikan ini dikenal juga dengan nama King of Aquarium. Bentuk badannya bulat seperti cakram dan gerakannya halus (Lingga \& Susanto, 1986). Berdasarkan warnanya ikan discus dikelompokkan menjadi empat jenis yaitu: heckel discus (Symphysodon discus), brown discus (Symphysodon aequifasciata), dan blue discus (Symphysodon haroldi). Para penggemar ikan discus sangat banyak, dan mereka juga banyak yang berkreasi untuk memunculkan varietas baru yang lebih bagus dan menarik, yang diminati oleh masyarakat. Dengan semakin berkembangnya kreativitas para pembudidaya ikan discus, saat ini telah muncul varietas-varietas baru lagi di antaranya red pigeon,
Marlboro, brown, blue, dan cobalt (Lesmana \& Dermawan, 2001).

Ikan discus termasuk salah satu golongan ikan hias mahal (ukuran 1 inci seharga Rp 7.000,-; jenis Marlboro ukuran 3 inci mencapai harga Rp 50.000,-; sedangkan kualitas ekspor ukuran 4 inci dapat mencapai harga $\mathrm{Rp}$ $150.000,-)$ dan eksotis khususnya untuk ikan introduksi (Komunikasi Pribadi, 2010). Mengingat hal tersebut, maka budidaya ikan discus perlu lebih dikembangkan agar dapat memenuhi pemintaan baik ekspor maupun domestik yang dari tahun ke tahun semakin meningkat. Salah satu produksi ikan discus terbesar dari Kabupaten Tangerang, dan ke depannya daerah ini akan lebih fokus mengembangkan komoditas ini. Pada Tabel 1 ditampilkan data statistik produksi benih dan nilai produksi benih yang dijual pada tahun 2008.

Budidaya ikan discus telah berkembang dan banyak dilakukan oleh para pembudidaya atau penghobist (para hobiis), meskipun ikan discus ini termasuk ikan hias yang lebih sulit pembudidayaannya dibandingkan ikan hias air tawar yang lainnya. Cara budidaya yang dilakukan oleh pembudidaya sampai sekarang adalah cara konvensional, sehingga hasil (benih) yang dihasilkan belum cukup memadai atau optimal. Anakan atau benih yang hidup masih relatif sedikit. Pada makalah ini akan memaparkan cara budidaya dengan manipulasi pakan larva. Sebagaimana diketahui bahwa larva ikan discus yg berumur 2-3 hari sampai satu minggu sangat tergantung dari lendir induk. Hal tersebut dapat menunda lebih lama induk ikan discus untuk memijah berikutnya dan kanibalisme induk tersebut terhadap larvanya sendiri. Artificial food (pakan buatan) untuk larva ini merupakan sebuah inovasi dari peternak ikan discus yang telah berhasil dikembangkan.

\section{BIOLOGI IKAN DISCUS}

Ikan discus merupakan salah satu ikan hias air tawar introduksi dari Sungai Amazon, Amerika Latin, dan mempunyai klasifkasi sebagai berikut (Lingga \& Susanto, 1986): 
Tabel 1. Data statistik nilai produksi benih ikan discus hasil budidaya

\begin{tabular}{ccccc}
\hline \multicolumn{3}{c}{ Kuartal } & & Total \\
\hline I & II & III & IV & \\
\hline 198,164 & 200,234 & 208,243 & 221,315 & 827,956 (ekor) \\
$4,954,100,000$ & $5,005,850,000$ & $5,206,075,000$ & $7,746,025,000$ & $22,912,050,000$ (Rp) \\
\hline
\end{tabular}

Sumber: Dinas Pertanian, Sub Dinas Binus Perikanan, Kota Tangerang (2008)

Filum : Chordata

Kelas : Osteichthyes

Sub kelas : Actinopterygii

Ordo : Percomorphoidei

Subordo : Percoidae

Famili : Cichlidae

Genus : Symphysodon

Spesies : Symphysodon discus

Ciri morfologi ikan discus secara umum berbentuk pipih bundar seperti cakram "disc" dengan ikan bawal. Warna dasar badannya coklat kemerahan, terdapat garisgaris berombak yang beraneka rupa tidak teratur mulai dari dahi sampai samping perut. Pada kepala dan badannya terpotong menjadi sembilan garis tegak. Tiga garis di antaranya nampak jelas, sedangkan untuk enam garis terlihat samar-samar. Badannya mempunyai garis tengah paling besar yaitu sampai $15 \mathrm{~cm}$ dan mempunyai mata yang selalu merah. Sedangkan morfologi secara umum ikan discus dapat dilihat pada Gambar 1. Sesuai dengan warna badannya ada beberapa varietas discus di antaranya adalah (Anonim, 2010):

\section{Heckel Discus (Symphysodon discus)}

Jenis discus tersebut mempunyai ciri-ciri garis pertama, kelima, dan kesembilan tampak sangat jelas, badan berbentuk harmonis, warna dasar badan adalah coklat hijau sampai coklat merah dan coklat biru. Garisgaris horizontal berwarna kelabu biru sampai hijau toska (torquise).
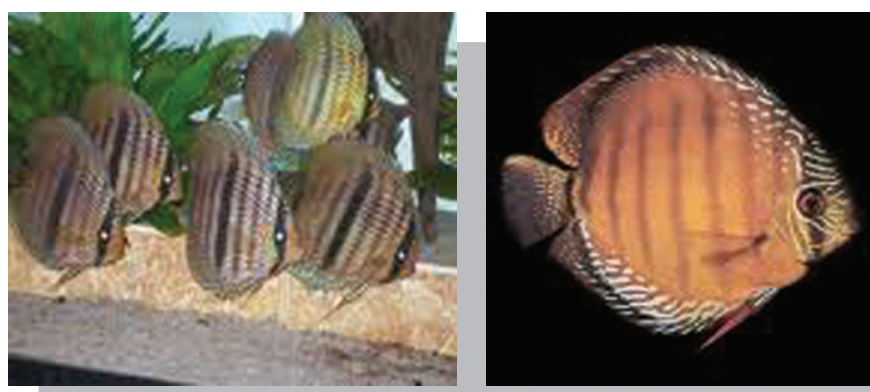

\section{Brown Discus (Symphysodon aequifasciata axelrodi)}

Ciri-ciri morfologi yang sangat jelas pada discus jenis ini adalah warna dasar badan beragam, dari kuning sampai coklat dan merah, dijumpai sejumlah kecil marking pada kepala, nape, dan sirip anal.

\section{Green Discus (Symphysodon aequifasciata aequifasciata)}

Secara morfologi discus ini berwarna hijau coklat sampai biru disertai dengan bintik-bintik merah pada badannya. Sirip anal berwarna hijau biru dengan bintikbintik merah dan bercak-bercak halus.

\section{Blue Discus (Symphysodon aequifasciata haroldi)}

Badan ikan discus jenis ini mempunyai badan dengan warna dasar biru atau coklat hingga biru dan atau hijau toska, garis-garis horizontal berwarna hijau toska dengan lebar beragam. Saat ini sudah puluhan variasi warna ikan hias discus seperti sunrise (merah), albino (putih), dan lain-lain.

Habitat ikan discus adalah pada suhu sekitar $25^{\circ} \mathrm{C}$ $30^{\circ} \mathrm{C}$, dengan kisaran $\mathrm{pH}$ yang cukup luas namun cenderung asam yaitu 5-6,5 dan kekerasan air lunak antara $3^{\circ} \mathrm{dH}-$ $5^{\circ} \mathrm{dH}$. Menurut pendapat sejumlah pembudidaya, akuarium untuk discus harus dijaga pada suhu $26^{\circ} \mathrm{C}-31^{\circ} \mathrm{C}$. Suhu optimal untuk discus dewasa adalah $29^{\circ} \mathrm{C}$, sedangkan larva discus harus dijaga pada suhu $31^{\circ} \mathrm{C}$. Pada kenyataannya discus dapat tumbuh dengan baik di akuarium yang penuh cahaya sama seperti ikan-ikan hias air tawar tropis lainnya. Discus membutuhkan penggantian air sebanyak 25\% volume tangki setiap minggunya. Penggantian air perlu
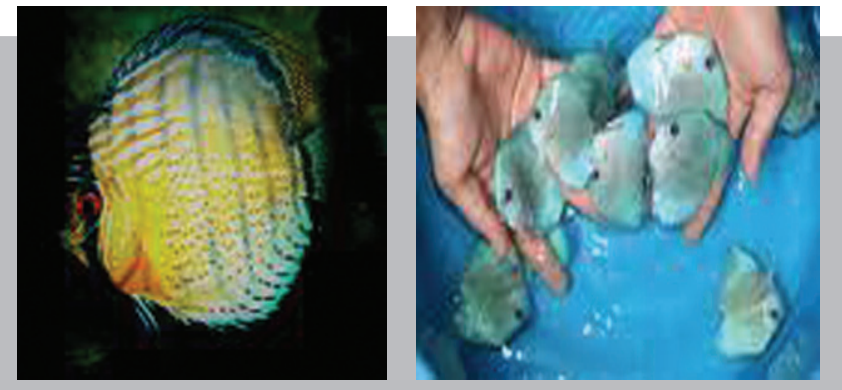

Gambar 1. Performa ikan discus dari kiri heckel, brown, green, dan blue discus 
dilakukan sesering mungkin untuk menjaga agar setiap parameter kualitas air tetap konstan. Jika tidak diganti, air akuarium akan dipenuhi nitrat serta amonium yang akan menghambat pertumbuhannya. Kadar amonia dan nitrit harus dijaga pada kadar $(<1 \mathrm{mg} / \mathrm{L})$; sementara kadar nitrit harus dijaga pada kadar serendah mungkin. Di sisi lain, penggantian air tak boleh terlalu banyak misalnya sampai mencapai $50 \%$. Hal itu akan membuat parameter air berfluktuasi dan pada akhirnya membuat discus menjadi stres. Sebaliknya, jika air diganti secara teratur, selera makan serta aktivitas kawin pada discus akan meningkat. Ikan discus yang baru ditangkap dari alam liar perlu dikarantina setidaknya 4-6 minggu dalam ruangan terpisah, tangki terpisah, dan peralatan pengganti air yang terpisah untuk mengeliminasi kemungkinan infeksi ikan baru ini pada penghuni lama. Penempatan discus baru ke kolam utama sendiri (yang berisi discus sebelumnya) diyakini harus dilakukan dalam kondisi gelap atau saat pemberian makan. Ikan discus di alam merupakan ikan omnivora oportunistik yang memakan invertebrata serta tumbuhan. Dalam pemeliharaan di akuarium ataupun tanki dapat diberi pakan alami yang berupa cacing, kutu air, ataupun pelet sebagai pakan tambahan.

\section{BUDIDAYA IKAN DISCUS CARA KONVENSIONAL}

Pola reproduksi ikan discus seperti halnya ikan siklid yang lain, yaitu dipasangkan (satu pasang dalam satu wadah). Pakan untuk induk yang berfungsi untuk mematangkan gonad adalah cacing darah, jentik nyamuk, pelet sebagai makanan tambahan. Telur biasanya diletakkan pada substrat. Substrat dapat dibuat dari paralon yang diletakkan pada pojok akuarium dengan posisi berdiri. Telur-telur biasanya menetas setelah dibuahi 2-3 hari. Telur dan larva ikan discus tidak dapat dipisahkan dari induknya. Larva akan tetap menempel pada induk-induknya sampai sekitar satu minggu (Gambar 2), karena makanan yang dimakan adalah lendir-lendir pada badan induk tersebut. Hal tersebut berlangsung sampai 21 hari walaupun dapat diberi pakan tambahan berupa Artemia atau pakan larva lainnya (Zein, 2010).

Menurut Lesmana \& Dermawan (2001), dalam beberapa hal induk-induk yang masih mengasuh larva, dapat memakan anakannya sendiri bila stres. Oleh karena itu, dalam pemeliharaan larva dibuat sekat pembatas antara induk dan larva. Selain makan dari lendir induk, pada saat larva sudah berenang dapat ditambahkan dengan pakan alami berupa artemia dan kutu air. Untuk menghindari induk maka arahnya dapat dilakukan dengan sistem "inang asuh" yaitu dicarikan induk khusus yang tidak suka makan anaknya.

Kondisi yang demikian rumit dalam memijahkan ikan discus tersebut sehingga benih yang dihasilkan sangat sedikit. Untuk mengatasi hal tersebut, inovasi praktisi pembudidaya ikan discus telah menemukan pakan buatan untuk larva yang menyerupai lendir ikan sebagai pengganti lendir induk. Larva atau burayak setelah menetas tidak lagi diasuh oleh induknya, tetapi diberi pakan lendir buatan.

\section{INOVASI ARTIFICIAL FOOD UNTUK LARVA IKAN DISCUS}

Telur yang diletakkan oleh induk di dalam substrat akan menetas sekitar 2-3 hari. Selama 6 hari larva tersebut masih mempunyai kuning telur. Setelah kuning telur habis larva akan berenang ke permukaan air. Pada saat itulah larva diangkat dan dipindahkan ke dalam baskom yang telah dilengkapi dengan aerasi dan diberi pakan buatan. Apabila tidak diangkat akan langsung menempel ke badan induknya.

Menurut Zein (2010), bahan dasar yang digunakan untuk membuat pakan larva buatan adalah dua butir telur ayam, satu butir direbus dan satu butir mentah. Kedua
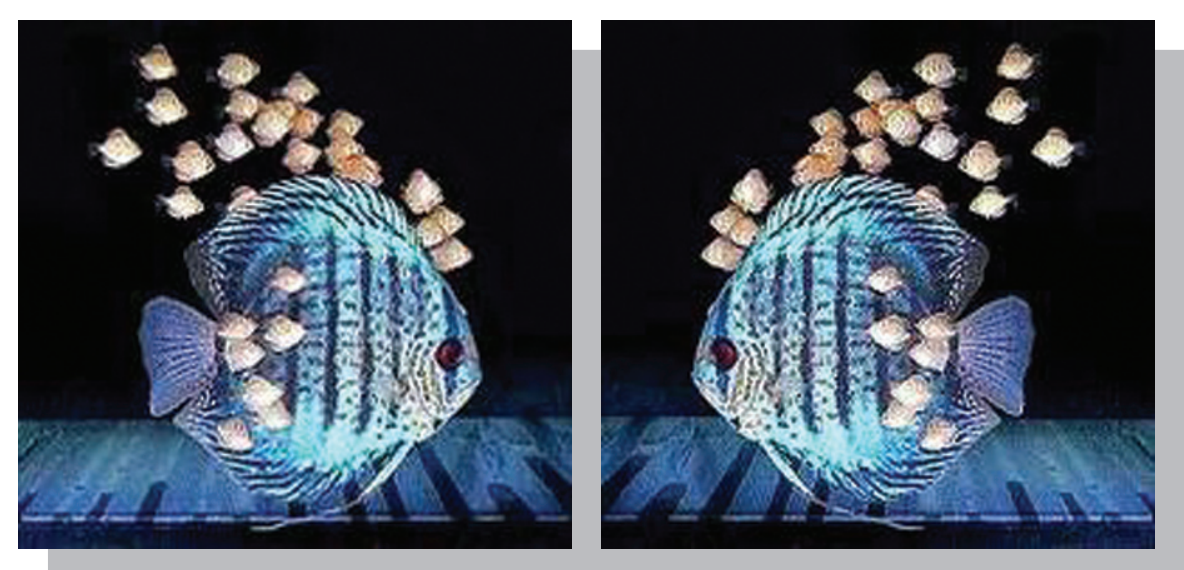

Gambar 2. Larva ikan discus yang memakan lendir-lendir induknya 
butir telur diambil kuningnya, dan diaduk merata sampai terlihat seperti lendir. Selanjutnya adonan telur tersebut dibekukan, dan penggunaan sedikit demi sedikit dioleskan pada paralon. Pipa paralon berukuran satu inci dibuat setinggi baskom dan dibersihkan. Pakan dioleskan sedikit demi sedikit ke permukaan potongan paralon tersebut sampai rata dan tipis. Selanjutnya paralon tersebut dibiarkan sampai kering sekitar 3 menit, kemudian diletakkan di dalam baskom tempat burayak dengan tegak lurus.

Selanjutnya dikatakan oleh Zein (2010), larva yang diberi pakan buatan langsung menempel pada paralon tersebut seolah-olah induknya. Larva dibiarkan memakan lendir sekitar satu jam dan setelah habis pakan, paralon diangkat dan dibersihkan kembali untuk dioleskan pakan

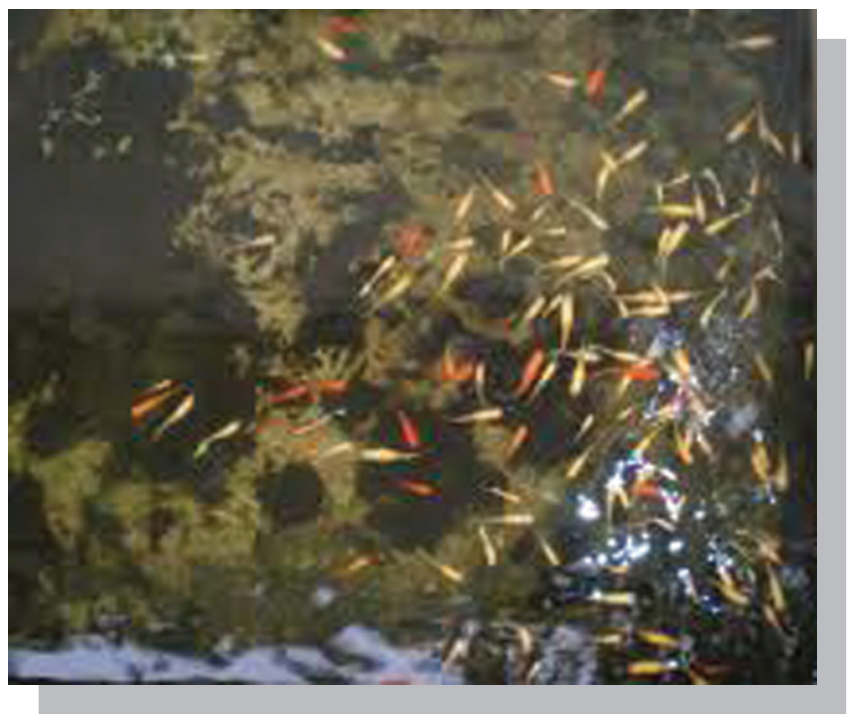

Gambar 3. Larva ikan discus kembali. Hal tersebut dilakukan secara berulang-ulang sampai malam hari. Sisa pakan yang berjatuhan di baskom disipon agar tidak menjadi racun bagi larva. Pada hari berikutnya larva diperlakukan kembali diberi pakan buatan tersebut. Pemberian pakan buatan tersebut dilakukan sampai 4 hari, selanjutnya hari kelima selain diberi pakan buatan sudah diperkenalkan pakan tambahan yaitu Artemia. Larva umur 10 hari sudah mulai diberikan pakan alami berupa Daphnia atau kutu air selanjutnya setelah larva berumur tiga minggu sudah mulai diberi makan cacing darah atau cacing sutra (Gambar 3).

\section{PENUTUP}

Budidaya ikan discus yang telah lama berkembang di kalangan hobiis dan pembudidaya, masih dijalankan secara tradisional. Hal tersebut hanya dapat menghasilkan benih yang terbatas, karena induk-induk memerlukan waktu lama dalam mengasuh larva, sehingga untuk mematangkan gonad kembali juga membutuhkan waktu yang lama. Pemberian pakan buatan tersebut selain dapat memacu pematangan gonad induk berikutnya juga menyelamatkan larva yang biasanya dimakan oleh induk-induknya.

\section{DAFTAR ACUAN}

Anonim. 2010. Berbagai Varietas Discus. Media Informasi Ikan Hias dan Tanaman Air. http://o-fish.com/Discus/ discus. php, 3 pp.

Lesmana, D.S. \& Dermawan, I. 2001. Budidaya Ikan Hias Air Tawar Populer. Penebar Swadaya, 159 hlm.

Lingga, P. \& Susanto, H. 1986. Ikan Hias Air Tawar. Penebar Swadaya, $236 \mathrm{hlm}$.

Zein, H.M. 2010. Budidaya Discus dengan Artificial Food, $4 \mathrm{hlm}$. 